\title{
THE BI-SUBSTITUTED HYDROXYAPATITE AS RADIO-OPAQUE MATERIAL *
}

\author{
Gabriela Ciobanu ${ }^{* *}$, Ana Maria Bargan ${ }^{\text {, }}$, Constantin Luca 1, Octavian Ciobanu ${ }^{2}$
}

1 "Gheorghe Asachi" Technical University of Iasi, Faculty of Chemical Engineering and Environmental Protection, Department of Organic, Biochemical and Food Engineering, Prof. dr. docent Dimitrie Mangeron, Iasi, Romania 2 "Grigore T. Popa" University of Medicine and Pharmacy, Faculty of Medical Bioengineering, Iasi, Romania

\begin{abstract}
This study relates to a new apatite material which is biocompatible and exhibits radio-opacity, enhancing its utility in the dental and medical fields. The bismuth-substituted hydroxyapatite was obtained by means of wet chemical method, that is, by co-precipitation reactions. The effects of the bismuth substitution for calcium on the morphology and optical proprieties of the resulting powder were investigated by scanning electron microscopy (SEM) coupled with X-ray analysis (EDX), X-ray powder diffraction (XRD) and X-ray photoelectron spectroscopy (XPS). Bi-substituted hydroxyapatite is radio-opaque, and it can be detected by X-rays and computed tomography.
\end{abstract}

Key words: Hydroxyapatite, bismuth, radio-opaque

DOI: $10.21175 /$ RadJ.2016.02.016

\section{INTRODUCTION}

In dental and orthopedic applications, radioopaque materials may be used as filler in the composition of the biocement paste in order to enhance absorption of X-rays, and therefore for improving the visibility of the cement under X-ray examination. Radio-opacity is important for uses of cements in dental filling and dental sealing.

Bismuth compounds, due to their radio-opacity, are added to various bone and dental implants, catheters and surgical instruments in order to make them detectable by X-rays and computed tomography [1].

The hydroxyapatite (HAp, $\left.\mathrm{Ca}_{10}\left(\mathrm{PO}_{4}\right)_{6}(\mathrm{OH})_{2}\right)$ is a calcium phosphate ceramic with important applications in the medicine and chemistry fields. The hydroxyapatite is a main mineral constituent of the hard tissues such as bones and teeth [2]. The hydroxyapatite has remarkable properties including biocompatibility, bioactivity and ability to form a direct chemical bond with human hard tissues [3-5].

The hydroxyapatite structure allows the incorporation of wide range of different ionic substitutions [6]. Numerous cations have been reported to substitute into the $\mathrm{Ca}$ sites in the hydroxyapatite structure $[7,8]$. Such ionic substitutions influences the properties (morphology, lattice parameters, surface characteristic, solubility, biological properties, etc.) and applications of these doped hydroxyapatite materials as biomaterials, catalysts, ion exchangers, etc. [9-12].

In this paper we present the preparation of new bismuth-substituted hydroxyapatite nanopowder, as radio-opaque material, by means of wet chemical method, respectively by co-precipitation reactions.

\section{EXPERIMENTAL}

\subsection{Materials and synthesizing methods}

Calcium hydroxide $\mathrm{Ca}(\mathrm{OH})_{2}$, orthophosphoric acid $\mathrm{H}_{3} \mathrm{PO}_{4}(85 \%)$, bismuth nitrate pentahydrate $\mathrm{Bi}\left(\mathrm{NO}_{3}\right)_{3} \cdot 5 \mathrm{H}_{2} \mathrm{O}$, ethanol $\mathrm{CH}_{3}-\mathrm{CH}_{2}-\mathrm{OH}$ and sodium hydroxide $\mathrm{NaOH}$ were purchased from SigmaAldrich (Germany). All chemicals were of analytical grade.

The hydroxyapatite and bismuth-substituted hydroxyapatite nanoparticles were synthesized by wet chemical precipitation method from $\mathrm{Ca}(\mathrm{OH})_{2}$, $\mathrm{H}_{3} \mathrm{PO}_{4}$ and $\mathrm{Bi}\left(\mathrm{NO}_{3}\right)_{3} \cdot 5 \mathrm{H}_{2} \mathrm{O}$ as calcium, phosphorous and bismuth sources, respectively.

The pure hydroxyapatite powder was prepared by mixing appropriate amounts of $\mathrm{Ca}(\mathrm{OH})_{2}(0.1 \mathrm{M})$ and $\mathrm{H}_{3} \mathrm{PO}_{4}(0.1 \mathrm{M})$ aqueous solutions to achieve predetermined $\mathrm{Ca} / \mathrm{P}$ atomic ratio of 1.67 [13]. The suspension obtained was aged for $3 \mathrm{~h}$ and then filtered and washed with ethanol and triply distilled water. The obtained powder was calcined $1 \mathrm{~h}$ at $800^{\circ} \mathrm{C}$ in an electrically heated furnace in order to increase its crystallinity.

The bismuth-substituted hydroxyapatite powder was prepared similarly to the pure hydroxyapatite powder, as described above. The $\mathrm{Ca}(\mathrm{OH})_{2}(0.1 \mathrm{M})$ aqueous solution was dispersed into an mixed aqueous solution of $\mathrm{Bi}\left(\mathrm{NO}_{3}\right)_{3} \cdot 5 \mathrm{H}_{2} \mathrm{O}$ and $\mathrm{H}_{3} \mathrm{PO}_{4}$ (0.1 $\mathrm{M})$. The $(\mathrm{Bi}+\mathrm{Ca}) / \mathrm{P}$ atomic ratio was kept at 1.67 value, while the $\mathrm{Bi} /(\mathrm{Bi}+\mathrm{Ca})$ atomic ratio (denoted as $X_{B i}$ ) in the solution was 0.1, as shown in Table 1. The following procedure stages were the same as

\footnotetext{
* The paper was presented at the Third International Conference on Radiation and Applications in Various Fields of Research (RAD 2015), Budva, Montenegro, 2015.
} 
described above for the preparation of pure hydroxyapatite powder.

Table 1. Atomic ratio in the synthesis solution and in the final products

\begin{tabular}{|c|c|c|}
\hline & \multicolumn{2}{|c|}{ Sample } \\
\cline { 2 - 3 } in synthesis solution: & HA-Bi-o & HA-Bi-10 \\
$\mathrm{Bi} /(\mathrm{Bi}+\mathrm{Ca})$ & $\mathrm{O}$ & \\
$(\mathrm{Bi}+\mathrm{Ca}) / \mathrm{P}$ & 1.677 & 0.1 \\
$\mathrm{Bi}(\%)$ & 0 & 1.677 \\
in final product: & & 10 \\
$\mathrm{Bi} /(\mathrm{Bi}+\mathrm{Ca})$ & $\mathrm{O}$ & 0.093 \\
$(\mathrm{Bi}+\mathrm{Ca}) / \mathrm{P}$ & 1.673 & 1.660 \\
$\mathrm{Bi}(\%)$ & 0 & 9.33 \\
\hline
\end{tabular}

\subsection{Samples characterization}

The phase composition, degree of crystallinity and size of crystallites of the calcined samples were estimated by X-ray diffraction analysis (XRD) with X'PERT PRO MRD diffractometer using CuKa radiation $(\lambda=0.15418 \mathrm{~nm})$.

The morphology of the calcined samples was studied by scanning electron microscopy (SEM) coupled with energy dispersive X-ray spectroscopy (EDX) with QUANTA 200 3D microscope.

The bismuth chemical valence on hydroxyapatite structure was evaluated by X-ray photoelectron spectroscopy (XPS) using a PHI-50oo VersaProbe photoelectron spectrometer ( $\Phi$ ULVAC-PHI, INC.) with a hemispherical energy analyzer (0.85 eV binding energy resolution).

The radiographs of the samples were obtained in a dental X-ray system (X-Mind ${ }^{\mathrm{TM}}$ AC, SATELEC, France).

\section{RESULTS AND DisCUSSION}

The incorporation of foreign ions in the hydroxyapatite structure is favorable when the difference between the ionic radii is small, closeness to the ionic radius of $\mathrm{Ca}^{2+}$ ion. According to Shannon [14], the effective $\mathrm{Ca}^{2+}$ ionic radii for seven- and nine-coordination are of $1.06 \AA$, and $1.18 \AA$, respectively. For $\mathrm{Bi}^{3}$ the ionic radii are of $1.03 \AA$ and $1.17 \AA$ in six- and eight-coordination, respectively. Having comparable dimensions, the $\mathrm{Bi}^{3+}$ ions can substitute $\mathrm{Ca}^{2+}$ ions during the synthesizing process.

In this study, the SEM-EDX analysis was performed in order to determine the surface elemental composition of the hydroxyapatite and Bisubstituted hydroxyapatite powders.

Fig. 1 shows the EDX spectra of HA-Bi-O and HA-Bi-10 samples, and for the last the characteristic peaks of bismuth are well evidenced. The samples contain calcium or/and bismuth, phosphorous, oxygen and hydrogen in certain contents. The mass fractions of different elements in the hydroxyapatite and Bi-substituted hydroxyapatite samples were obtained and the atomic ratios calculated as shown in Table 1.

The value of the $\mathrm{Bi} /(\mathrm{Bi}+\mathrm{Ca})$ atomic ratio (designated $\mathrm{X}_{\mathrm{Bi}}$ ) in the final product was very close to the $\mathrm{X}_{\mathrm{Bi}}$ in the synthesis solution for Bi-substituted hydroxyapatite sample, as shown in Table 1 . This indicates that the bismuth ions added to the synthesis solution are incorporated into the hydroxyapatite lattice. Furthermore, the value of the $(\mathrm{Bi}+\mathrm{Ca}) / \mathrm{P}$ atomic ratio in the final product (Table 1$)$ is very close to the theoretical value of 1.677 for the stoichiometric hydroxyapatite [15]. This result indicates that the isomorphous substitution $\mathrm{Ca} \leftrightarrow \mathrm{Bi}$ does not significantly affect the stoichiometry of the Bi-substituted hydroxyapatite sample.
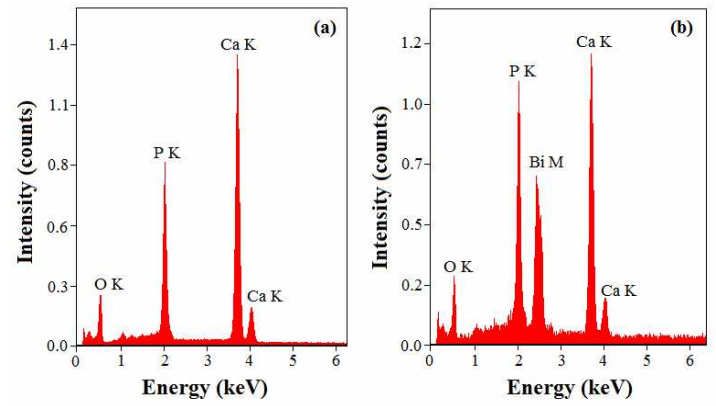

Figure 1. EDX spectra of the HA-Bi-o (a) and HA-Bi-10 (b) calcined samples

The apatite samples exhibit nanosized spherical shapes and agglomeration with intergranular micropores, as shown SEM micrographs in Fig. 2. The Bi content in apatite does not result in strong changes in morphology but greater agglomeration.
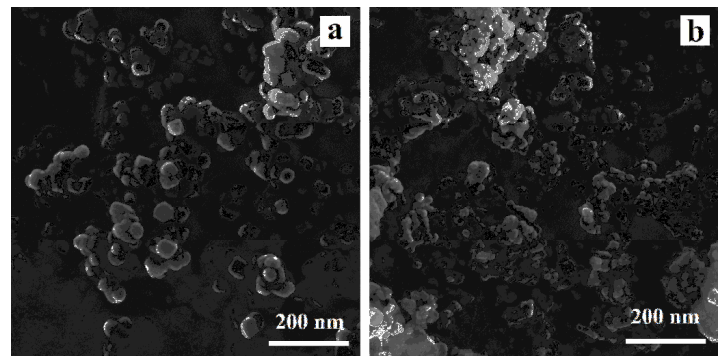

Figure 2. SEM images of the HA-Bi-O (a) and HA-Bi-10 (b) calcined samples

The phase composition, lattice parameters, degree of crystallinity and size of crystallites of the samples were determined by XRD analysis and the obtained results are shown in Fig. 3 and Table 2. The XRD patterns in Fig. 3 are in good agreement with the hexagonal (space group P63/m) hydroxyapatite phase (JCPDS Data Card 09-0432). However, the patterns displayed some extra peaks indicating that the samples contain very small amounts of impurities. Thus, a peak of at $2 \theta \approx 37.5^{\circ}$ indicates the presence of calcium oxide traces in the final 
products, perhaps due to insufficient control of the precipitation reaction. Fortunately, these traces represent a biodegradable phase and the biodegradable property is a key factor in the promotion of bone-like cell growth over the bone implant surface [16].

The XRD pattern of the Bi-substituted hydroxyapatite sample shows the peaks broader and less intense compared with the pure hydroxyapatite. This indicates the decrease of crystallinity due to bismuth contents (Table 2), which could be attributed to different charge compensation mechanism for isomorphous substitution of $\mathrm{Ca}^{2+}$ by $\mathrm{Bi}^{3+}$ ions. Also, the broad peaks indicated that the hydroxyapatite particles are of a nanometric size (Table 2).

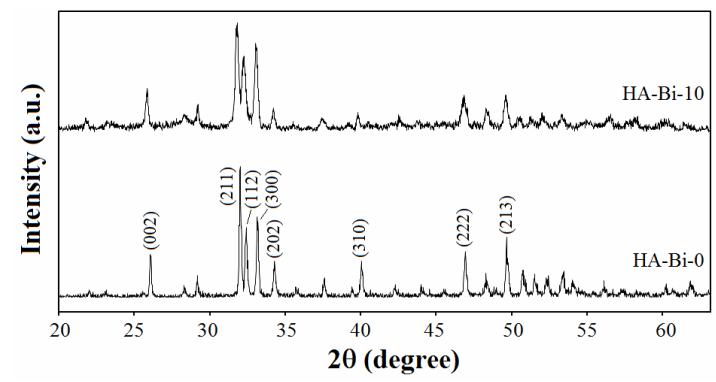

Figure 3. XRD patterns of the hydroxyapatite and Bisubstituted hydroxyapatite samples

Table 2. XRD data of the hydroxyapatite and Bisubstituted hydroxyapatite samples

\begin{tabular}{|c|c|c|}
\hline \multirow{2}{*}{} & \multicolumn{2}{|c|}{ Sample } \\
\cline { 2 - 3 } & HA-Bi-O & HA-Bi-10 \\
\hline$D(\mathrm{~nm})$ & 58.32 & 44.19 \\
$X_{C}(\%)$ & 99.78 & 90.97 \\
$V(\AA 3)$ & 1605.77 & 1627.17 \\
$a(\AA)$ & 9.5271 & 9.5514 \\
$c(\AA)$ & 6.8333 & 6.8892 \\
\hline
\end{tabular}

The XPS analysis was applied to study the surface chemical state of undoped and Bi substituted hydroxyapatite and the results present the evidence for the successful doping of $\mathrm{Bi}$ ions in hydroxyapatite lattice. Thus, Fig. 4 shows the XPS spectrum of the HA-Bi-10 sample for the binding energy range of $\mathrm{o}-1200 \mathrm{eV}$.

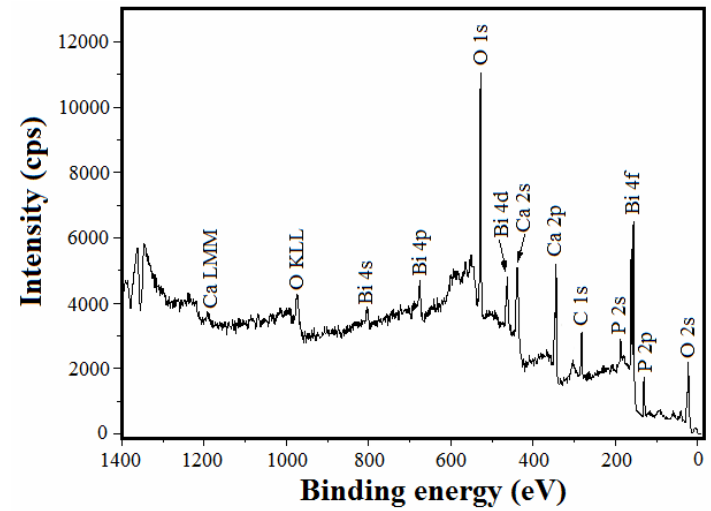

Figure 4. XPS spectrum of the HA-Bi-10 sample

It can be seen that the binding energy of $\mathrm{Bi}(4 \mathrm{f}$ region, $150-170 \mathrm{eV}$; peaks at $156.70 \mathrm{eV}$ and 162 $\mathrm{eV}$ ), Ca (2p, $345 \mathrm{eV}), \mathrm{O}(1 \mathrm{~s}, 529 \mathrm{eV})$ and P (2p, 131 $\mathrm{eV})$ are detected. The $\mathrm{P} 2 \mathrm{p}$ core level peak located at $131 \mathrm{eV}$ is attributed to $\mathrm{P}-\mathrm{O}$ bonds in $\mathrm{PO}_{4}{ }^{3-}$ chemical environment [17]. The $\mathrm{C}$ 1s $(282.7 \mathrm{eV})$ signal is due to the carbon used as an internal reference. No other impurities were evident in the samples, in good agreement with the XRD data. Therefore, the XPS data demonstrate that the HAp lattice contain $\mathrm{Bi}^{3+}$ ions.

The radio-opacity of the hydroxyapatite and Bisubstituted hydroxyapatite samples was analyzed and the results are presented in Fig. 5. Bisubstituted hydroxyapatite sample shows a much stronger radio-opacity compared with undoped hydroxyapatite, as can see in Fig. 5 .

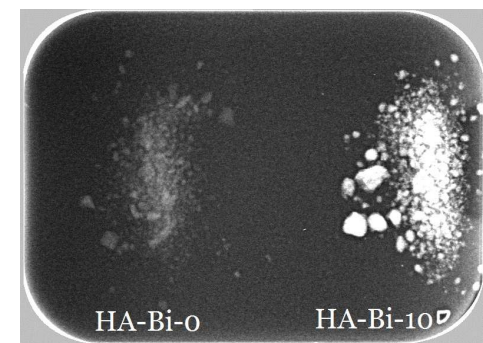

Figure 5. Radiograph images of the hydroxyapatite and Bisubstituted hydroxyapatite samples

Due to their radio-opacity, the Bi-substituted hydroxyapatite can be added to various bone and dental implants, catheters and surgical instruments in order to make them detectable by X-rays and computed tomography.

\section{CONCLUSIONS}

The experimental results revealed that the $\mathrm{Bi}$ substituted hydroxyapatite nanopowder was produced by the co-precipitation method using $\mathrm{Ca}(\mathrm{OH})_{2}, \mathrm{H}_{3} \mathrm{PO}_{4}$ and $\mathrm{Bi}\left(\mathrm{NO}_{3}\right)_{3} \cdot 5 \mathrm{H}_{2} \mathrm{O}$ raw materials, as calcium, phosphorous and bismuth sources. The Bi content is close to $10 \%$. The XPS analysis of the 
doped sample indicated the $\mathrm{Bi}$ presence in the apatite lattice as $\mathrm{Bi}^{3+}$. The XRD results indicate that the Bi substitution did not change the crystal structures. Bi-substituted hydroxyapatite sample is radio-opaque, being detectable by $\mathrm{X}$-rays and computed tomography.

\section{REFERENCES}

1. M. Stoltenberg, S. Juhl and G. Danscher, "Bismuth ions are metabolized into autometallographic traceable bismuth-sulphur quantum dots", Eur. J. Histochem., vol. 51, pp. 53-57, 2007.

2. F.C.M. Driessens, "The mineral in bone, dentin and tooth enamel", Bull. Soc. Chim. Belg., vol. 89, pp. $663-689,1980$

3. L.L. Hench H.A. and Paschall, "Direct chemical bonding of bioactive glass-ceramic materials and bone", J. Biomed. Mater. Res. Symp., vol. 4, pp. 2542, 1973 .

4. N. Patel et al., "A comparative study on the in vivo behaviour of hydroxyapatite and silicon-substituted hydroxyapatite granules", J. Mater. Sci.: Mater. Med., vol. 13, pp. 1199-1206, 2002.

5. Y. Doi, T. Shibutani, Y. Moriwake, T. Kajimoto and Y. Iwayama, "Sintered carbonate apatites as bioresorbable bone substitutes", J. Biomed. Mater. Res., vol. 39, pp. 603-610, 1997.

6. T. Tamm and M. Peld, "Computational study of cation substitutions in apatites", J. Solid State Chem., vol. 179, pp. 1581-1587, 2006.

7. J.H. Shepherd, D.V. Shepherd and S.M. Best, "Substituted hydroxyapatites for bone repair", $J$. Mater. Sci. - Mater. M., vol. 23, pp. 2335-2347, 2012.

8. V. Aina et al., "Magnesium- and strontium-cosubstituted hydroxyapatite: the effects of doped-ions on the structure and chemico-physical properties", $J$. Mater. Sci. Mater. Med., vol. 23, pp. 2867-2879, 2012.
9. I.R. Lima et al., "Understanding the impact of divalent cation substitution on hydroxyapatite: An in vitro multiparametric study on biocompatibility", J. Biomed. Mater. Res. A, vol. 98A, pp. 351-358, 2011.

10. T.N. Kim et al., "Antimicrobial effects of metal ions $\left(\mathrm{Ag}^{+}, \mathrm{Cu}^{2+}, \mathrm{Zn}^{2+}\right)$ in hydroxyapatite", J. Mater. Sci. Mater. Med., vol. 9, pp. 129-134, 1998.

11. N. Rameshbabu et al., "Antibacterial nanosized silver substituted hydroxyapatite: synthesis and characterization”, J. Biomed. Mater. Res. A, vol. 8oA, pp. 581-591, 2007.

12. A.M. Bargan, G. Ciobanu, C. Luca and E. Horoba, "Influence of the citric acid on the cerium substituted hydroxyapatite morphology", Studia UBB Chemia, vol. 4, pp. 137-145, 2013.

13. G. Ciobanu, S. Ilisei, M. Harja and C. Luca, "Removal of Reactive Blue 204 dye from aqueous solutions by adsorption onto nanohydroxyapatite", Sci. Adv. Mater., vol. 5, pp. 1090-1096, 2013.

14. R.D. Shannon, "Revised effective ionic radii and systematic studies of interatomie distances in halides and chaleogenides", Acta Crystallogr. A, vol. 32, pp. 751-767, 1976.

15. D.G. Guo, A.H. Wang, Y. Han and K.W. Xu, "Characterization, physicochemical properties and biocompatibility of La-incorporated apatites", Acta Biomater., vol. 5, pp. 3512-3523, 2009.

16. S. Murugan and S. Ramakrishna, "Development of cell-responsive nanophase hydroxyapatite for tissue engineering", Am. J. Biochem. Biotechnol., vol. 3, pp. 118-124, 2007.

17. R.J. Chung, M.F. Hsieh, R.N. Panda and T.S. Chin, "Hydroxyapatite layers deposited from aqueous solutions on hydrophilic silicon substrate", Surf. Coat. Tech., vol. 165, pp. 194-200, 2003. 